\title{
First-Line Treatment in the Eradication of Helicobacter Pylori: where are we now?
}

\author{
Fatih Ciftci ${ }^{1 *}$ and Turgut Anuk ${ }^{2}$ \\ ${ }^{1}$ Istanbul Gelisim University, Turkey \\ 2Kafkas University, Turkey
}

Submission: December 13, 2016; Published: January 23, 2017

"Corresponding author: Fatih Ciftci, Istanbul Gelisim University, Vocational School of Health Services, Basakmah, Bulvar İstanbul sitesi E-4/79 34306, Basaksehir/Istanbul-Turkey, Tel: +905056164248; Fax: +902124627056; Email: oprdrfatihciftci@gmail.com

\begin{abstract}
Aim: Helicobacter pylori (HP) are the most common human infectious agent worldwide. Approximately half of the patients remain infected after 'eradication' treatment with the triple regimen of a proton pump inhibitor (PPI), amoxicillin (AMO), and clarithromycin (CLA). In this study, this PPI-based triple regimen was compared to a quadruple regimen, including bismuth citrate (BC), a PPI, metronidazole (MET), and tetracycline (TET), and BPMT.

Methods: Total 215 patients who were treated with lansoprozole (LAN), AMO and CLA (LAC); and another 210 patients who were treated with BPMT for 14 days for the purpose of HP eradication between January 2011 and April 2014 were included in this study. The treatment period was 14 days for both groups.

Results: Demographic characteristics and endoscopic findings were similar in both groups. The HP eradication rate was \% 53.4 in the LAC group, and it was \%78.5 in the BPMT group $(\mathrm{P}<0.05)$. The rates of non-compliance with treatment and side effects were higher in the BPMT group $(\mathrm{P}<0.05)$. Among all, 55 patients in the LAC group and 110 patients in the BPMT group were reported to have had difficulties conforming to the treatment $(\mathrm{P}=0.020)$. In the questionnaire on the side effects of the drugs, 30 patients in the LAC group and 90 in the BPMT group gave positive answers $(P=0.006)$. The most frequently reported side effects were dry mouth and metallic taste. The eradication rates were $\% 53.4$ in the LAC regimen, and \%78.5 in the BPMT regimen. This difference was statistically significant $(\mathrm{P}=0.026)$.
\end{abstract}

Conclusion: The efficacy of LAC for HP eradication in Turkey has diminished due to high microbial resistance to antibiotics. The BPMT regimen should be considered a first-line treatment because of its higher eradication rate. We suggest that BPMT could be accepted as a firstline treatment for acute HP infection. LAC is an alternative treatment for a select group of patients.

Keywords: Helicobacter pylori; Eradication; Triple regimen; Quadruple regimen

\section{Introduction}

Helicobacter pylori (HP) are the most common human infectious agent worldwide [1]. In some countries the prevalence is up to $85-90 \%$ [2]. It plays a role in the aetiology of many gastric disorders including adenocarcinoma, and is associated with some haematological, neurological, and cardiovascular conditions [37]. Since the discovery of HP, the triple regimen treatment has been used as the standard approach for its eradication. This consists of a PPI and two antibiotics, usually AMO and CLA [1,5,7-29]. In recent years other antibiotics have also been used $[30,31]$. Because of the development of microbial resistance to CLA worldwide, more attention has been paid to alternative therapies. Thus, a BC-containing quadruple regime has been widely used in recent years $[1,4,5,7,15,17,19,21,25,27,32-40]$. Recent studies carried out in our country have indicated that microbial resistance to CLA has risen beyond \%50, rendering the success of the classical triple regimen unacceptably poor $[3,16,20,26,28,41,42]$.

Given all of these studies, alternatives to the standard PPI regimen have drawn the attention of clinicians. In our clinic, HP eradication treatment now consists of a 14-day course of oral tablets, consisting of a BC $600 \mathrm{mg}$ tablet BID, a PPI (OME 200 mg or LAN $30 \mathrm{mg}$ ) capsule BID, an MET $500 \mathrm{mg}$ tablet TID, and a TET $500 \mathrm{mg}$ tablet QID. This is the quadruple BPMT regimen. Our previous approach used to be the triple regimen of a LAN 


\section{Advanced Research in Gastroenterology \& Hepatology}

30 mg capsule BID, an AMO 1000 mg tablet BID, and a CLA 500 mg tablet BID. In the present study, we compared these two commonly applied first-line treatments to the eradication of HP.

In our country, there are endoscopy units in most general surgery hospitals. HP is the most common infection throughout the world and has been shown to be associated with gastric cancer. Thus, data concerning HP eradication are a matter of concern not for only for medical gastroenterologists but also for general surgeons.

\section{Patients and Methods}

Total 425 patients who underwent endoscopic biopsies and were found to have HP infection received 14-day treatments for HP eradication. Following the treatment, a second endoscopy and a urea breath test (Heliprobe, Noster AB, Sweden) or an HP stool antigen test (Antigen card test, Dialab, Austria) were done to evaluate the rate of eradication. The patients were divided into two groups: group I (LAC) and group II (BPMT). The patients were randomised into LAC and BPMT groups with a computergenerated random number. The patients were evaluated for eradication rate, difficulty in conforming to the treatment, and drug side effects. Smoking habits, alcohol consumption, and use of other drugs were also recorded. Reports of pathological examinations were scrutinised for the presence of precancerous lesions and these results were also recorded. All study participants, or their legal guardian, provided written informed consent prior to study enrolment.

\section{Statistical Analysis}

The SPSS software (ver. 15.0; SPSS Inc., Chicago, IL, USA) was used to analyse the data. The $\chi 2$ test was used for comparisons. $\mathrm{P}$ values $<0.05$ were considered to indicate statistical significance.

\section{Results}

There were 215 patients in the 'classical' LAC group and 210 in the BPMT group. Patient demographic characteristics, comorbidities, smoking habits, alcohol consumption habits, and use of other drugs were similar between the groups $(\mathrm{P}>0.05)$ (Table 1). There were also no significant differences between the groups in terms of endoscopic biopsy findings ( $\mathrm{P}>0.05$ ) (Table 2).

Table 1: Patients characteristics according to their groups.

\begin{tabular}{|c|c|c|c|}
\hline & LAC (n = 213) & BPMT (n = 210) & P-Value \\
\hline $\begin{array}{c}\text { Age: mean (range) } \\
\text { years }\end{array}$ & $48.2(25-80)$ & $43.5(18-75)$ & \\
\hline Gender: (M/F) & $\begin{array}{c}100 / 115(\mathrm{M}: \\
46.5 \%)\end{array}$ & $\begin{array}{c}100 / 110(\mathrm{M}: \\
47.6 \%)\end{array}$ & 0.917 \\
\hline Co-morbidities & $75(34.8 \%)$ & $65(30.9 \%)$ & 0.621 \\
\hline Smoking habits & $55(25.5 \%)$ & $50(23.8 \%)$ & 0.776 \\
\hline $\begin{array}{c}\text { Alcohol } \\
\text { consumption }\end{array}$ & $20(9.3 \%)$ & $15(71 \%)$ & 0.616 \\
\hline Other drug use & $105(48.8 \%)$ & $90(42.8 \%)$ & \\
\hline
\end{tabular}

\begin{tabular}{|c|c|c|c|}
\hline -NSAID & 40 & 35 & \\
\hline -Anti hypertensive & 30 & 25 & \\
\hline -Anti diabetics & 25 & 25 & \\
\hline -Anti depressants & 10 & 5 & 0.531 \\
\hline
\end{tabular}

LAC: lansoprazole, amoxicillin, and clarithromycin triple regimen, BPMT: bismuth citrate, proton pump inhibitor, metronidazole, and tetracycline quadruple regimen, M: male, F: female, NSAID: nonsteroidal anti-inflammatory drug.

Table 2: Endoscopic biopsy findings in the groups.

\begin{tabular}{|c|c|c|c|}
\hline $\begin{array}{c}\text { Endoscopic Biopsy Findings (HP } \\
\text { Gastritis and Ulcers) }\end{array}$ & LAC & BPMT & $\boldsymbol{P}$-value \\
\hline Intestinal metaplasia & 40 & 40 & 1 \\
\hline Tubular/tubulovillous adenoma & 10 & 5 & 0.256 \\
\hline Oedematous gastric mucosa & 5 & 10 & 0.256 \\
\hline Gastric dysplasia & 0 & 5 & 0.563 \\
\hline Carcinoid tumour & 0 & 5 & 0.563 \\
\hline
\end{tabular}

HP: Helicobacter Pylori; LAC: Lansoprazole Amoxicillin and Clarithromycin Triple Regimen; BPMT: Bismuth Citrate Proton Pump Inhibitor Metronidazole and Tetracycline Quadruple Regimen

In all, 55 patients in group 1 and 110 patients in group II reported difficulties in conforming to the treatments $(\mathrm{P}=0.020)$. In the questionnaire for drug side effects, 30 patients in group I and 90 in group II reported positive answers $(P=0.006)$. The most frequently reported side effects were dry mouth and metallic taste. Evaluating eradication rates, the LAC regimen was $\% 53.4$ successful and the BPMT regimen was \%78.5 successful. This difference was statistically significant $(P=0.026)$ (Table 3$)$.

Table 3: Rates of difficulties in conforming to treatment, side effects and eradication in the groups.

\begin{tabular}{|c|c|c|c|}
\hline & LAC & BPMT & P-value \\
\hline $\begin{array}{c}\text { Difficulty in conforming } \\
\text { with treatment }\end{array}$ & $55(25.5 \%)$ & $110(52.3 \%)$ & 0.02 \\
\hline Side effects & $30(13.9 \%)$ & $90(42.8 \%)$ & \\
\hline -Dry mouth & 10 & 30 & 0.006 \\
\hline -Metallic taste & 15 & 25 & 0.006 \\
\hline -Abdominal pain & 5 & 15 & \\
\hline -Nausea vomiting & 0 & 20 & 0.026 \\
\hline Eradication & $115(53.4 \%)$ & $165(78.5 \%)$ & \\
\hline
\end{tabular}

LAC: Lansoprazole Amoxicillin and Clarithromycin Triple Regimen; BPMT: Bismuth Citrate Proton Pump Inhibitor Metronidazde and Tetracycline Quadruple Regimen.

\section{Discussion}

HP is a Gram-negative spiral bacteria and the most common infectious agent worldwide. It is estimated that about half of the global population is infected. It is an important factor in the aetiology of gastritis, gastric and duodenal ulcers, gastric mucosaassociated lymphoma (MALT), and gastric adenocarcinoma [3-6]. 
Recent studies have shown that HP infection is also associated with some diseases outside the gastrointestinal system, including refractory iron deficiency anaemia, idiopathic thrombocytopenic purpura (haematological system) paralysis, Parkinson's disease, Alzheimer's disease (neurological system), and ischemic heart disease (cardiovascular system) [7].

Since the discovery of HP in 1983, diagnostic and therapeutic approaches to gastritis and peptic ulcers have changed greatly [29]. In 1994, the World Health Organization International Agency for Research on Cancer reached the conclusion that HP has a causative relationship with gastric carcinogenesis and that the agent is a definite carcinogen in humans [43]. Since then, much more attention has been focused on this agent. In the Mongolian gerbil model, it was shown that HP could induce gastric cancer independent of exposure to low-dose chemical carcinogens [44]. In the early 2000s, survey studies carried out in Japan showed that HP infection increased the risks of intestinal metaplasia and diffuse-type gastric cancer [29,45]. The estimated risk of developing cancer attributable to HP varies between $\% 50$ and \%73(46). In a randomised study carried out in Colombia that included patients with high-risk and precancerous lesions, it was observed that there was a significant decrease in cancer rate among those who had HP eradicated [46]. In another randomised study carried out in China, HP eradication significantly decreased the risk of gastric cancer in individuals without gastric atrophy and intestinal metaplasia or dysplasia [47]. The benefit of HP eradication on gastric cancer has been a subject in other studies too. A study in Japan showed that gastric cancer risk in the residual stomach after distal gastrectomy and Billroth I anastomosis for previous gastric cancer decreased significantly subsequent to HP eradication [48].

Currently, various treatment protocols are being used for the eradication of HP. It was reported that prior to the 2000s, the triple regimen was successful at a rate of $\% 95$ [18]. However, with the development of microbial resistance to CLA, this success rate has decreased to $\% 5522$. Thus, there has recently been a trend towards the quadruple regimen including $\mathrm{BC}$, which has anti-HP and mucosal cytoprotective effects. For this reason, it is expected that protocols including BC will be effective [49]. Indeed, some studies have shown this regimen to be effective $[5,13]$.

In this study, we compared the most commonly used firstline treatment protocols. The choice of OME or LAN as the PPI in BPMT depends on the clinician's preference. However, a previous study reported no significant differences between various PPIs in terms of efficacy [50]. In the present study, a second endoscopic examination, and a urea breath test or HP stool antigen test was done at least 8 weeks after treatment to evaluate the rate of eradication. Other studies have shown that these tests have the same value and their sensitivities and specificities exceed $\% 90$ [51-54]. The use of different PPI drugs did not seem to have affected our results.
There were no significant differences between our patient groups in terms of their general characteristics and endoscopic biopsy findings. However, the rate of difficulty in conforming to treatment and side effects were higher in the BPMT group. This could be due the high number of tablets prescribed (13 tablets daily) and the high doses. Indeed, other studies have also referred to difficulties in the use of the BPMT protocol [3]. Patients are advised to take the drugs after meals and to drink a lot of water to minimise the side effects of the antibiotics. Other studies have proposed the use of probiotics to minimise the side effects of antibiotics and increase eradication $[7,15]$.

Evaluation of the eradication rates in our study showed a $\% 78.5$ success rate in the BPMT group and \% 53.4success in the LAC group.

This difference was statistically significant. The low success rate in the LAC group is consistent with the results of other studies carried out in our country and is attributed to increased microbial resistance to CLA $[16,20,42]$. A meta-analysis in our country showed that the success rate of the triple regimen was \%79.4 in 1996 and decreased to \%61.1 in 2005 [26]. In recent years, this rate has been estimated to be \% 50-55 [20]. Although the success rate with BPMT was higher (\%78.5) than that with $\mathrm{LAC}$, this rate was well below expectations. The reason for this could be the growing resistance to MET in our country and worldwide $[3,7,22]$.

Other treatment approaches should be considered for cases where eradication is unsuccessful. Currently, various alternative regimens are being used. These include successive, combination, hybrid, and rescue regimens, some of which include the use of levofloxacin and the classical anti-tuberculosis agent rifabutin $[7,15]$. Limitations of our study included patient's not completing follow-up, reporting too late for re-evaluation, and insufficient information being obtained from the patients.

\section{Conclusion}

A 14-day treatment with the BPMT regimen was more successful than the classical LAC regimen for HP eradication. In some patients, drug side effects and difficulty conforming to the treatment were a problem. In cases of unsuccessful eradication, other regimens described in the literature should also be considered.

\section{References}

1. Altintaş E, Ulu O, Sezgin O, Aydin O, Camdeviren H (2004) Comparison of ranitidine, bismuth citrate, tetracycline and metronidazole with ranitidine, bismuth citrate and azithromycin for the eradication of Helicobacter pylori in patients resistant to PPI based triple therapy. Turk J Gastroenterol 15(2): 90-93.

2. Önder T, Hasbal NB, Kahramanca Ş, Anuk T (2006) The Relationship Between Helicobacterpylori Infection and Sex, Blood Group sand Rhesus Factor in Patients with Chronic Gastritis. IKSST Derg 8(2): 9396.

3. Wong WM, Gu Q, Lam SK, Fung FM, Lai KC, et al. (2003) Randomized controlled study of rabeprazole, levofloxacin and rifabutin triple 
therapy vs. quadruple therapy as second-line treatment for Helicobacter pylori infection. Aliment Pharmacol Ther 17(4): 553-560.

4. Köksal AS, Onder FO, Torun S, Parlak E, Sayilir A, et al. (2013) Twice a day quadruple therapy for the first-line treatment of Helicobacter pylori in an area with a high prevalence of background antibiotic resistance. Acta Gastroenterol Belg 76(1): 34-37.

5. Frenck RW, Clemens J (2003) Helicobacter in the developing world. Microbes Infect 5(8): 705-713.

6. Zheng Q, Chen WJ, Lu H, Sun QJ, Xiao SD (2010) Comparison of the efficacy of triple versus quadruple therapy on the eradication of Helicobacter pylori and antibiotic resistance. J Dig Dis 11(5): 313-318.

7. Georgopoulos SD, Papastergiou V, Karatapanis S (2013) Current options for the treatment of Helicobacter pylori. Expert Opin Pharmacother 14(2): 211-223

8. Suzuki H, Matsuzaki J, Hibi T (2011) Metronidazole-based quadruple versus standard triple therapy: which is better as first-line therapy for Helicobacter pylori eradication? Expert Rev Clin Pharmacol 4(5): 579582 .

9. Marko D, Calvet X, Ducons J, Guardiola J, Tito L, et al. (2005) Comparison of two management strategies for Helicobacter pylori treatment: clinical study and cost-effectiveness analysis. Helicobacter 10(1): 2232.

10. Buzás GM (2010) First-line eradication of Helicobacter pylori: are the standard triple therapies obsolete? A different perspective. World J Gastroenterol 16(31): 3865-3870.

11. Tsukanov VV, Amelchugova OS, Butorin NN, Tretiakova OV, Vasiutin AV (2013) Helicobacter pylori eradication: current status. Ter Arkh 85(2) 73-75.

12. Gené E, Calvet X, Azagra R, Gisbert JP (2003) Triple vs quadruple therapy for treating Helicobacter pylori infection: an updated metaanalysis. Aliment Pharmacol Ther 18(5): 543-544.

13. Dore MP, Farina V, Cuccu M, Mameli L, Massarelli G, et al. (2011) Twicea-day bismuth-containing quadruple therapy for Helicobacter pylori eradication: a randomized trial of 10 and 14 days. Helicobacter 16(4): 295-300.

14. Xu MH, Zhang GY, Li CJ (2011) Efficacy of bismuth-based quadruple therapy as first-line treatment for Helicobacter pylori infection. Zhejiang Da Xue Xue Bao Yi Xue Ban 40(3): 327-331.

15. O'Connor A, Molina-Infante J, Gisbert JP, O’Morain C (2013) Treatment of Helicobacter pylori infection 2013. Helicobacter 18(Suppl 1): 58-65.

16. Uygun A, Ozel AM, Yildiz O, Aslan M, Yesilova Z, et al. (2008) Comparison of three different second-line quadruple therapies including bismuth subcitrate in Turkish patients with non-ulcer dyspepsia who failed to eradicate Helicobacter pylori with a 14-day standard first-line therapy. J Gastroenterol Hepatol 23(1): 42-45.

17. Seyedmajidi S, Mirsattari D, Zojaji H, Zanganeh E, Seyyedmajidi M, et al. (2013) Penbactam for Helicobacter pylori eradication: a randomised comparison of quadruple and triple treatment schedules in an Iranian population. Arab J Gastroenterol 14(1): 1-5.

18. Ching CK, Chan YK, Ng WC (1998) The combination of omeprazole, amoxycillin, and clarithromycin eradicates Helicobacter pylori in 95\% of patients-7 days of therapy is as good as 10 days. Hong Kong Med J 4(1): 7-10.

19. Wang Z, Wu S (2012) Doxycycline-based quadruple regimen versus routine quadruple regimen for rescue eradication of Helicobacter pylori: an open-label control study in Chinese patients. Singapore Med J 53(4): 273-276.

20. Nadir I, Yonem O, Ozin Y, Kilic ZM, Sezgin O (2011) Comparison of two different treatment protocols in Helicobacter pylori eradication. South Med J 104(2): 102-105.
21. Marin AC, McNicholl AG, Gisbert JP (2013) A review of rescue regimens after clarithromycin-containing triple therapy failure (for Helicobacter pylori eradication). Expert Opin Pharmacother 14(7): 843-861.

22. Wong WM, Gu Q, Wang WH, Fung FM, Berg DE, et al. (2003) Effects of primary metronidazole and clarithromycin resistance to Helicobacter pylori on omeprazole, metronidazole, and clarithromycin tripletherapy regimen in a region with high rates of metronidazole resistance. Clin Infect Dis 37(7): 882-889.

23. Wong WM, Xiao SD, Hu PJ, Wang WH, Gu Q et al. (2005) Standard treatment for Helicobacter pylori infection is suboptimal in nonulcer dyspepsia compared with duodenal ulcer in Chinese. Aliment PharmacolTher 21(1): 73-81.

24. Gisbert JP, Perez-Aisa A, Rodrigo L, Molina-Infante J, Modolell I, et al. (2014) Third-line rescue therapy with bismuth-containing quadruple regimen after failure of two treatments (with clarithromycin and levofloxacin) for H. pylori infection. Dig Dis Sci 59(2): 383-389.

25. Chung JW, Lee GH, Han JH, Jeong JY, Choi KS, et al. (2011) The trends of one-week first-line and second-line eradication therapy for Helicobacter pylori infection in Korea. Hepato gastroenterology 58(105): 246-250.

26. Kadayifci A, Buyukhatipoglu H, CemilSavas M, Simsek I (2006) Eradication of Helicobacter pylori with triple therapy: an epidemiologic analysis of trends in Turkey over 10 years. Clin Ther 28(11): 19601966.

27. Venerito M, Krieger T, Ecker T, Leandro G, Malfertheiner P (2013) Metaanalysis of bismuth quadruple therapy versus clarithromycin triple therapy for empiric primary treatment of Helicobacter pylori infection. Digestion 88(1): 33-45.

28. Gumurdulu Y, Serin E, Ozer B, Kayaselcuk F, Ozsahin K, et al. (2004) Low eradication rate of Helicobacter pylori with triple 7-14 days and quadruple therapy in Turkey. World J Gastroenterol 10(5): 668-671.

29. Uemura N, Okamoto S, Yamamoto S, Matsumura N, Yamaguchi S, et al. (2001) Helicobacter pylori infection and the development of gastric cancer. N Engl J Med 345(11): 784-789.

30. De Boer WA, Driessen WM, Jansz AR, Tytgat GN (1995) Quadruple therapy compared with dual therapy for eradication of Helicobacter pylori in ulcer patients: results of a randomized prospective singlecentre study. Eur J Gastroenterol Hepatol 7(12): 1189-1194.

31. De Boer WA, Driessen WM, Tytgat GN (1995) Only four days of quadruple therapy can effectively cure Helicobacter pylori infection. Aliment Pharmacol Ther 9(6): 633-638.

32. Salazar CO, Cardenas VM, Reddy RK, Dominguez DC, Snyder LK, et al. (2012) Greater than 95\% success with 14-day bismuth quadruple antiHelicobacter pylori therapy: a pilot study in US Hispanics. Helicobacter 17(5): 382-390.

33. Moon JY, Kim GH, You HS, Lee BE, Ryu DY, et al. (2013) Levofloxacin, metronidazole, and lansoprazole triple therapy compared to quadruple therapy as a second-line treatment of Helicobacter pylori infection in Korea. Gut Liver 7(4): 406-410.

34. De Boer SY, Meeberg PC, Siem H, de Boer WA (2003) Comparison of four-day and seven-day pantoprazole-based quadruple therapy as a routine treatment for Helicobacter pylori infection. Neth J Med 61(6): 218-222.

35. Vekens K, Vandebosch S, De Bel A, Urbain D, Mana F (2013) Primary antimicrobial resistance of Helicobacter pylori in Belgium. Acta Clin Belg 68(3): 183-187.

36. Kamberoglou D, Polymeros D, Sanidas I, Doulgeroglou V, Savva S, et al. (2001) Comparison of 1-week vs. 2- or 4-week therapy regimens with ranitidine bismuth citrate plus two antibiotics for Helicobacter pylori eradication. Aliment Pharmacol Ther 15(9): 1493-1497. 
37. Wong WM, Huang J, Xia HH, Fung FM, Tong TS, et al. (2005) Lowdose rabeprazole, amoxicillin and metronidazole triple therapy for the treatment of Helicobacter pylori infection in Chinese patients. J Gastroenterol Hepatol 20(6): 935-940.

38. Mégraud F (2013) Current recommendations for Helicobacter pylori therapies in a world of evolving resistance. Gut Microbes 4(6): 541548

39. Buzás GM (2010) Helicobacter pylori-2010. OrvHetil 151(49): 20032010.

40. Castro-Fernández M, Lamas E, Pérez-Pastor A, Pabón M, Aparcero R, et al. (2009) Efficacy of triple therapy with a proton pump inhibitor, levofloxacin, and amoxicillin as first-line treatment to eradicate Helicobacter pylori. Rev EspEnferm Dig 101(6): 395-402.

41. Shiota S, Yamaoka Y (2013) Strategy for the treatment of Helicobacter pylori infection. Curr Pharm 20(28): 4459-4500.

42. Ergül B, Doğan Z, Sarikaya M, Filik L (2013) The efficacy of two-week quadruple first-line therapy with bismuth, lansoprazole, amoxicillin, clarithromycin on Helicobacter pylori eradication: a prospective study. Helicobacter 18(6): 454-458.

43. IARC Working Group on the evaluation of carcinogenic risks to humansschistosomes, liver flukes and Helicobacter pylori. Lyon, 7-14 June 1994. IARC Monogr Eval Carcinog Risks Hum 61: 1-241.

44. Sugiyama A, Maruta F, Ikeno T, Ishida K, Kawasaki S, et al. (1998) Helicobacter pylori infection enhances N-methyl-N-nitrosoureainduced stomach carcinogenesis in the Mongolian gerbil. Cancer Res 58(10): 2067-2069.

45. Yamagata H, Kiyohara Y, Aoyagi K, Kato I, Iwamoto H, et al. (2000) Impact of Helicobacter pylori infection on gastric cancer incidence in a general Japanese population: the Hisayama study. Arch Intern Med 160(13): 1962-1968.

46. Correa P, Fontham ET, Bravo JC, Bravo LE, Ruiz B, et al. (2000) Chemoprevention of gastric dysplasia: randomized trial of antioxidant supplements and anti-helicobacter pylori therapy. J Natl Cancer Inst 92(23): 1881-1888.

47.Wong BC, Lam SK, Wong WM, Chen JS, Zheng TT, et al. (2004) Helicobacter pylori eradication to prevent gastric cancer in a high-risk region of China: a randomized controlled trial. JAMA 291(2): 187-194.

48. Hamaguchi K, Ogawa K, Katsube T, Konno S, Aiba M (2004) P Does eradication of Helicobacter pylori reduce the risk of carcinogenesis in the residual stomach after gastrectomy for early gastric cancer? Comparison of mucosal lesions in the residual stomach before and after Helicobacter pylori eradication. Langenbecks Arch Surg 389(2): 83-91.

49. Aydın A, Günşar F, Yılmaz M, Karasu Z, Özütemiz Ö, et al. (1999) Ranitidine bismuth citrate based dual and triple therapies in Helicobacter pylori eradication. Turk J Gastroenterol 10: 202-206.

50. Keum B, Lee SW, Kim SY, Kim JM, Choung RS, et al. (2005) Comparison of Helicobacter pylori eradication rate according to different PPIbased triple therapy-omeprazole, rabeprazole, esomeprazole and lansoprazole. Korean J Gastroenterol 46(6): 433-439.

51. Monteiro L, De Mascarel A, Sarrasqueta AM, Bergey B, Barberis C, et al. (2001) Diagnosis of Helicobacter pylori infection: noninvasive methods compared to invasive methods and evaluation of two new tests. Am J Gastroenterol 96(2): 353-358.

52. Özbalcı GS, Yürüker SS, Tarım IA, Çınar H, Ayfer Polat K, et al. (2014) Helikobakterpilori eradikasyonunda birinci basamak tedavi: bir cerrahi kliniğinin deneyimleri. Ulusal Cerrahi Derg 30-33.

53. Hwang JJ, Lee DH, Lee AR, Yoon H, Shin CM, et al. (2015) Efficacy of 14-d vs 7-d moxifloxacin-ased triple regimens for second-line Helicobacter pylori eradication. World J Gastroenterol 21(18): 5568-5574.

54. Ribaldone DG, Fagoone S, Astegiano M, Saracco G, Pellicano R (2015) Efficacy of amoxycllin and clarithromycin-based triple therapy for Helicobacter pylori eradication: a 10-year trend in Turin, Italy. Panminerva Med 57(3): 145-146.

\section{Your next submission with Juniper Publishers will reach you the below assets}

- Quality Editorial service

- Swift Peer Review

- Reprints availability

- E-prints Service

- Manuscript Podcast for convenient understanding

- Global attainment for your research

- Manuscript accessibility in different formats

( Pdf, E-pub, Full Text, Audio)

- Unceasing customer service

Track the below URL for one-step submission https://juniperpublishers.com/online-submission.php 